\title{
Propensão a Empreender: uma investigação quantitativa BASEADA NAS CARACTERÍSTICAS EMPREENDEDORAS DE ALUNOS do Curso de Administração
} r

\author{
Tendency to Undertake: a quantitative research \\ based on the entrepreneurial characteristics of business \\ undergraduated students
}

Hong Yuh Ching

Coordenador do Curso de ADM Centro Universitário FEI. São Bernardo do Campo, SP, Brasil. E-mail:hongching@fei.edu.br

José Renato Kitahara

Professor. Centro Universitário FEI. São Bernardo do Campo, SP, Brasil.E-mail:jrenatok@usp.br

\section{Resumo}

O objetivo principal desta pesquisa é identificar e analisar as características comportamentais empreendedoras nos estudantes de uma Instituição de Ensino Superior (IES) da região metropolitana de São Paulo. Seus resultados foram comparados aos resultados obtidos em outros estudos correlatos realizados no Brasil. Como referencial teórico, foi utilizado o instrumento desenvolvido por McClelland com 10 características comportamentais. A pesquisa é aplicada quanto a sua natureza e com objetivo descritivo. A amostra vem de um grupo de alunos do curso de Administração de uma IES da Grande São Paulo. Uma análise quantitativa das respostas foi realizada. Os resultados mostram que as características mais desenvolvidas foram Estabelecimento de Metas e Comprometimento, enquanto as menos desenvolvidas foram Persuasão e Correr Riscos Calculados. As pontuações obtidas na classificação das características comportamentais desse estudo são similares às dos demais estudos correlatos. Uma contribuição diferenciada deste estudo é a proposição de um modelo matemático resultante da variável latente da Análise Fatorial, que representa o grau de disposição em empreender.

Palavras-chave: Empreendedorismo. Características Empreendedoras. Modelo de McClelland.

\section{Abstract}

The objective of this paper is to identify and analyze the entrepreneurial behavioral characteristics in the undergrad students of a Business course. The results were compared with those from other correlated studies performed in Brazil. The instrument developed by McClelland with 10 behavioral characteristics was used as reference. This is an applied research with descriptive objective. The sample consists of a group of students of a higher education institute located in Great $S$ Paulo. The results show that the most developed characteristics were Setting Goals and Commitment while the least developed were Persuasion and Running Calculated Risks. The scores obtained in this study are similar to those in other correlated studies. A significative contribution of this study is the proposal of a mathematical model resulting from the latent variable of factor analysis, which represents the degree of willingness to undertake.

Keywords: Entrepreneurship. Entrepreneurial Characteristics. McClelland Model. 


\section{INTRODUÇÃO}

Segundo conceitua o SEBRAE (2007), empreendedorismo é o processo de criar algo novo com valor, dedicando o tempo e o esforço necessários, assumindo os riscos financeiros, psíquicos e sociais correspondentes e recebendo as consequentes recompensas da satisfação e independência econômica e pessoal.

Dornelas (2008) coloca que empreendedorismo significa fazer algo novo, diferente, mudar a situação atual e buscar, de forma incessante, novas oportunidades de negócio, tendo como foco a inovação e a criação de valor. Para Menezes (2003), o empreendedor, a partir de um comportamento criativo e inovador, sabe transformar contextos, estimular a colaboração, criar relacionamentos pessoais, gerar resultados, fazendo o que gosta de fazer, com entusiasmo, dedicação, autoconfiança, otimismo e necessidade de realização.

Os empreendedores são vitais para a saúde econômica de um país, eles geram empregos, estimulam o crescimento econômico e introduzem inovações tecnológicas (SOUZA, 2001). Empreendedorismo é visto como um motor do progresso econômico, criação de empregos e ajuste social além de ter um papel crítico para economias de países em desenvolvimento (GUROL; ATSAN, 2006). Tanto os grandes empreendedores como os pequenos são responsáveis pela geração de riquezas do país, sendo influenciadores na atual realidade dos negócios no Brasil e, apesar dos relativos progressos, o empreendedorismo no Brasil está apenas começando e necessita de um olhar especial do Governo (SOUZA, 2001).

O estudo do GEM (2013), confirmando as contribuições mencionadas, mostra que a Taxa de Empreendedores Iniciais (TEA) no Brasil atualmente corresponde a $17,3 \%$. Isso significa que, a cada 100 brasileiros, 17 estão envolvidos com uma atividade empreendedora (12 por oportunidade e cinco por necessidade) há menos de 42 meses. Com $71 \%$ dos Empreendedores Iniciais por oportunidade, o país está à frente dos cinco países do grupo dos BRICS, em que a proporção de empreendedores por oportunidade chegou a $61 \%$ na Índia, 65\% na Rússia, 66\% na China e na $70 \%$ na África do Sul.

A formação de novas empresas tem uma forte relação com o universo educacional, e como parte deste universo, as Universidades têm a capacidade de influenciar a mudança de rotas adotadas pelas corporações existentes no País, pois delas saem os profissionais que renovam as posições de comando no mercado, assim como os pensadores responsáveis por analisar e direcionar a economia nacional (BATISTA, 2004).

O Relatório do Estudo Mundial sobre Empreendedorismo junto aos Estudantes Universitários Brasileiros (GUESS Brasil) enfatiza que, a partir dos anos de 1990, as competências empreendedoras passaram a ser consideradas como importantes aliadas do desenvolvimento social e econômico (LIMA et al., 2011).

No atual contexto de mudança e avanço tecnológico, a estrutura de emprego modifica-se e assim, novas carreiras, qualificações e ocupações surgem, requerendo do sistema de ensino o desenvolvimento de novas competências. Essas competências necessitam de um ambiente que proporcione este desenvolvimento e cabe à universidade o papel de dispersão da cultura empreendedora (SOUZA et al., 2006).

A mesma ideia é reforçada em Dolabela (2008), que coloca a Universidade como o início deste processo de inserção na cultura empreendedora, por ser uma forte formadora de opinião e disseminadora do saber além de ter um papel importante na promoção do empreendedorismo entre seus estudantes (PADILLA-MELÉNDEZ et al., 2014). Educação transmite o conhecimento e habilidades capazes de mudar as intenções empreendedoras dos estudantes em atividades empreendedoras (IZEDONMI; OKAFOR, 2010).

Para Souza (2001), desenvolver o perfil empreendedor é capacitar o aluno para que ele crie, conduza e execute o processo de elaborar novos planos de vida. É importante desenvolver uma consciência para formação de pessoas disseminadoras da inovação $e$ das características básicas para formação de empreendedores.

Assim como explanado pelos autores supracitados, conhecer os componentes específicos das características comportamentais empreendedoras oferece um diagnóstico do quadro atual e futuro do empreendedorismo no âmbito universitário. Para tanto, o objetivo principal desta pesquisa é identificar e analisar as características comportamentais empreendedoras nos estudantes de uma IES da região metropolitana de São Paulo. Alguns dos seus resultados foram comparados com os resultados obtidos em outros estudos correlatos realizados no Brasil e no exterior. 
Uma contribuição diferenciada deste estudo foi a proposição de um modelo matemático linear multivariado resultante da variável latente da Análise Fatorial, que representa o grau de disposição em empreender, a partir das dez características empreendedoras proposta por McClelland e descrito em Mansfileld et al (1987).

\section{Referencial Teórico}

Nos estudos de empreendedorismo é possível identificar fatores ou características que influenciam o comportamento empreendedor. Padilla-Meléndez et al. (2014) dividem esses estudos em duas categorias com respeito as suas áreas de estudo: contexto e características pessoais. Contexto tem a ver com educação empreendedora, diferenças regionais, cultura, capital social, etc., enquanto a segunda área foca mais em desenvolver instrumento para medir orientação empreendedora relacionada às características psicológicas. Para Gurol e Arsan (2006) os fatores são individual, social e ambiental. Os fatores sociais tratam do passado pessoal e familiar e experiências de vida. Os ambientais examinam os fatores contextuais como oportunidades na carreira, o impacto das condições de mercado $e$ perturbação social enquanto os individuais focam nas características de personalidade dos empreendedores.

Esse estudo irá tratar dos fatores ou características pessoais ou individuais. São abordados quatro modelos que tratam de identificar as características empreendedoras e suas aplicações pelos pesquisadores - o modelo do McClelland, de Kristiansen e Indarti, do IMAE e a escala de Santos - bem como estudos correlatos sobre características comportamentais.

\subsection{Modelo de David McClelland}

David McClelland foi um dos primeiros a usar as teorias da ciência comportamental para realizar estudos de cunho empírico sobre a motivação para empreender, ele procurou estabelecer uma conexão entre a necessidade de realização e o desenvolvimento econômico de determinadas sociedades (OLIVEIRA, 2010).

Com o objetivo de fomentar o empreendedorismo, McClelland fundou a McBer \& Company, uma empresa de consultoria. Esta empresa, em uma parceria com a Management Systems International (MSI), realizou diversos estudos e treinamentos com o objetivo já citado, através de estímulos nas competências empreendedoras (BARTEL, 2010).

Em uma destas parcerias foi realizado, a pedido da USAID (United States Agency for International Development), um estudo que visava a identificação de características comportamentais empreendedoras em países emergentes. Primeiramente foram elaborados alguns instrumentos que pudessem avaliar tais características. Foi então que em 1987, após quatro anos de pesquisas, foi publicado o relatório final do projeto que apresentava sua aplicação em três países. Para as aplicações foram escolhidos três países: Equador, Índia e Malásia. Após essas aplicações, os autores chegaram à versão final de um questionário que seria capaz de mensurar as características comportamentais empreendedoras. Sendo validada a sua aplicabilidade, por atingir o objetivo, que era o de construir uma ferramenta que seria capaz de proporcionar o desenvolvimento da eficiência dos treinamentos em prol do empreendedorismo (MANSFILELD et al., 1987).

O questionário supracitado partia dos princípios de três grandes grupos (Necessidade de Realização, Planejamento e Poder). Destes grupos derivavam treze características, que eram mensuradas através de 1970 afirmações (cinco para cada uma das 13 características) em que os respondentes foram questionados a colocar, através de uma escala Likert de cinco pontos, o quanto eles concordavam com a afirmação ( $1=$ nunca,..., 5 = sempre). As cinco afirmações restantes, que não pertenciam a nenhuma característica, faziam parte de um fator de correção criado com o objetivo de controlar caso o indivíduo tentasse passar uma melhor imagem de si mesmo nas respostas (MANSFILELD et al.,1987).

Após alguns anos, a pedido da United Nations Conference on Trade and Development (UNCTAD), a Universidade de Harvard, em parceria com David McClelland, desenvolveu a metodologia do programa EMPRETEC, baseada no estudo já realizado por McClelland (UNCTAD, 2010). Nessa formulação ainda foram utilizados os três grandes constructos (Necessidade de Realização, Planejamento e Poder); houve, porém, uma adaptação e as 13 características tornaram-se 10. Concomitantemente, as 70 afirmações foram reduzidas para 55 (5 para cada uma das 10 características e as cinco restantes para uso como fator de correção de escala). Como a escala Likert de cinco pontos foi 
mantida, cada característica varia de 5 a 25 pontos, o autor considera que a partir de 15 pontos o participante já apresenta uma propensão a empreender. Este questionário pode ser encontrado em Paletta (2001). O Quadro 1 ilustra a distribuição das dez Características Comportamentais Empreendedoras (CCEs).

\begin{tabular}{|c|c|c|}
\hline \multicolumn{3}{|c|}{ MODELO - EMPRETEC } \\
\hline $\begin{array}{c}\text { NeCESsidade de } \\
\text { ReAlização }\end{array}$ & $\begin{array}{l}\text { NeCessidade de } \\
\text { Planejamento }\end{array}$ & $\begin{array}{c}\text { NeCESSIDADE DE } \\
\text { Poder }\end{array}$ \\
\hline $\begin{array}{l}\text {-Busca de } \\
\text { Oportunidades } \\
\text { e Iniciativa } \\
\text {-Comprometimento } \\
\text {-Persistência } \\
\text {-Correr riscos } \\
\text { calculados } \\
\text {-Exigência de } \\
\text { qualidade e } \\
\text { eficiência }\end{array}$ & $\begin{array}{l}\text {-Estabelecimento } \\
\text { de Metas } \\
\text {-Planejamento e } \\
\text { Monitoramento } \\
\text { Sistemáticos } \\
\text {-Busca de } \\
\text { Informações }\end{array}$ & $\begin{array}{l}\text {-Independência e } \\
\text { Autoconfiança } \\
\text {-Persuasão e Redes } \\
\text { de Contatos }\end{array}$ \\
\hline
\end{tabular}

Quadro 1: Distribuição CCEs modelo Empretec

Fonte: Elaborado pelos autores deste artigo

A aplicação do mesmo instrumento pode ser encontrada em outros estudos: Feger et al. (2008) que estudaram quais seriam as possíveis diferenças existentes no perfil empreendedor entre empreendedores privados e sociais de Santa Catarina, do ponto de vista de suas atitudes, ações, objetivos e estratégias; Silva (2009) que investigou as CCEs em estudantes de Administração de quatro IES do estado do Piauí; Bartel (2010) que monitorou a evolução das CCEs durante seis anos de estudantes de Administração de Santa Catarina, apresentando uma considerável amostra no estudo; Fonseca (2010) que mensurou a evolução das CCEs de empreendedores que haviam participado do curso Empretec no estado de Minas Gerais; Oliveira (2010) que comparou o perfil empreendedor e a efetividade empresarial de empreendedores do Rio Grande do Norte; Vasconcelos (2011) que analisou as características empreendedoras dos proprietários-dirigentes de micro e pequenas indústrias do ramo têxtil no estado do Piauí; Depositário et al. (2011) que avaliaram quais seriam as diferenças no perfil empreendedor entre estudantes de uma IES, pesquisadores da área de tecnologia e empreendedores das Filipinas; Câmara e Andalécio (2012) que aferiram a propensão a empreender de estudantes com formação em Farmácia em Belo Horizonte e, por fim, Carvalho e Zuanazzi
(2003) que analisaram as CCEs em estudantes de Administração de uma IES de Santa Catarina.

\subsection{O Modelo de Kristiansen e Indarti}

O estudo desenvolvido por Kristiansen e Indart (2004) objetivou a mensuração da intenção empreendedora, estabelecendo-se para tal uma série de fatores como elementos responsáveis pela intenção de empreender e os diferencia em três grupos: 1) fatores demográficos e contexto individual; 2) personalidades e atitudes; e 3) elementos contextuais. Para mensurar esta intenção empreendedora foi elaborado um questionário constituído de duas partes, a primeira responsável por traçar um perfil demográfico e a segunda responsável pela análise das variáveis de personalidades $e$ atitudes mencionadas. Esta última era constituída por 15 afirmações distribuídas em cinco construtos (Necessidade de Realização, Lócus de Controle, Auto eficácia, Busca por Informações e Intenção Empreendedora) e os respondentes deveriam responder dentro de uma escala do tipo Likert, variando de 1 a 7 (1= discordo totalmente a $7=$ concordo totalmente). Para a validação do instrumento foi aplicado primeiramente em estudantes da Noruega e da Indonésia.

Após a publicação deste modelo, outros pesquisadores se utilizaram deste modelo. Um deles foi o apresentado por Nascimento et al. (2010) que traduziram o instrumento de Kristiansen e Indarti para o português e o aplicaram em estudantes alagoanos de 4 diferentes universidades.

\subsection{Modelo Instrumento de Medida da Atitude Empreendedora (IMA)}

Este modelo foi criado por Lopez Junior e Souza (2006) e originou-se do estudo realizado por McClelland. Porém, ao invés de utilizarem 3 dimensões, foi adicionada uma $4^{\text {a }}$ (Inovação). Essas dimensões não derivavam de 55 afirmações como no instrumento de McClelland e sim de 36 afirmações. Os autores chegaram a esse número após algumas aplicações, em que foi validado o instrumento final.

Bornia et al. (2013) citam as validações do presente instrumento em empresários do Distrito Federal que eles desenvolveram por meio de outros trata- 
mentos estatísticos, como o da Teoria da Resposta ao Item (TRI).

\subsection{Uma Escala para Identificar o Potencial Empreendedor}

Santos (2008) parte da ideia de que não foi encontrada ainda uma escala, produzida no Brasil, fácil de ser aplicada, já validada e sem restrições quanto ao seu uso, para auxiliar na identificação do potencial empreendedor em estudantes, para o treinamento de empresários ou para a seleção de candidatos ao ingresso em incubadoras de empresas. Para o alcance deste objetivo foram definidos cenários, fatores, constructos e itens que permitiram a elaboração de um questionário que, após o teste de campo, pôde gerar essa escala. A escala em questão é na realidade uma adaptação do modelo proposto por McClelland, com diferença na inclusão de uma $4^{a}$ dimensão que seria o grupo responsável pela intenção de empreender. As escalas derivam de 57 afirmações cujos participantes devem selecionar, dentro de uma escala Likert de 11 pontos, o seu grau de concordância. A inovação proposta nesta escala estaria na inclusão de vinhetas e cenários antes das frases, o que levaria, segundo o autor, a um melhor entendimento por parte dos participantes. Este modelo foi utilizado por Toledo et al. (2011) que avaliaram empreendedores no estado de Alagoas.

Ao ponderar todos os instrumentos abordados, constata-se uma clara distinção do instrumento criado por McClelland. Bartel (2010) cita que os estudos realizados por McClelland abrangeram três continentes durante muitos anos, mostrando sua adaptabilidade a diferentes culturas, solidificando o grau de desenvolvimento do instrumento. Embora seja uma escala antiga, Feger et al. (2008) colocaram que ela foi amplamente testada em diversos países e apresentou diversas aplicações por estudiosos do tema. Um outro argumento forte a favor do instrumento de McClelland é o seu uso, até hoje, pelo programa EMPRETEC da UNCTAD. Apesar de o instrumento ser alvo de algumas críticas, pela sua forma simplória de análise do potencial empreendedor, Oliveira (2010) coloca que essas são decorrência de uma má leitura ou interpretação da obra de McClelland, pois para ele, há uma separação entre a propensão e o ato em si. Portanto, possuir traços, demonstrar interesse ou viver uma cultura em- preendedora, não significa que o indivíduo vá optar pelo empreendedorismo. É pertinente destacar que dos diversos modelos criados por outros autores, muitos são adaptações do modelo elaborado por McClelland, conforme cita Bartel (2010).

Pelas razões já apresentadas, os autores preferiram utilizar o instrumento do McClelland para efeitos desse trabalho.

\subsection{Estudos Correlatos sobre Características Comportamentais}

Izedonmi e Okafor (2010) examinaram o efeito da educação empreendedora nas intenções empreendedoras de 250 estudantes de uma universidade na Nigéria e se tal intenção promove surgimento de empreendimentos nesses estudantes. Seus resultados revelam que a exposição dos estudantes à educação empreendedora tem uma positiva influência nas intenções empreendedoras desses estudantes.

Essa mesma posição é compartilhada por Kume et al. (2013) em que a educação empreendedora no currículo tem um efeito positivo nas atitudes dos estudantes universitários da Albânia para uma carreira empreendedora. Outro achado desse estudo foi que a exposição anterior do estudante para o empreendedorismo, através do histórico familiar em negócios, está significativamente ligada às suas atitudes e comportamentos empreendedores. Esse achado também foi confirmado por Gurol e Atsan (2006) em que 53\% dos estudantes com inclinação para empreendedorismo tinham pais com negócio próprio. Comparado com os alunos que não tinham inclinação, apenas 19\% tinham pais com negócio próprio.

A pesquisa de Padilla-Meléndez et al. (2014) focou em como mudanças nas competências emocionais influenciam intenção empreendedora nos estudantes universitários espanhóis. Os resultados indicam que auto-gestão e gestão do relacionamento foram significativos na orientação empreendedora, particularmente na inovação e risco.

O estudo de Gurol e Atsan (2006) em estudantes universitários turcos mostra que os alunos com uma inclinação para empreendedorismo são mais inovadores, têm mais incentivos para sucesso, mais controle interno e mais tendência para assumir riscos em relação aos seus colegas que não têm essa inclinação. 
Por outro lado, os resultados de Sutanto e Eliyana (2014), nos estudantes universitários da Indonésia, mostram que existem relações significativas entre motivação para realização e atitude e características empreendedoras notadamente autoconfiança para assumir riscos e encontrar novas oportunidades $e$ motivação para realização.

Enquanto os cincos trabalhos anteriores pesquisaram jovens universitários em diversos países, o próximo pesquisou empresários já estabelecidos. Álvarez-Herranz et al. (2011) analisaram, com base nos dados da GEM Global Entrepreneurship Monitor de 2002 a 2006, a influencia dos perfis sócio demográficos dos empreendedores novos e nascentes em 22 países nos seus comportamentos. Seus resultados mostram que suas características influenciam o comportamento empreendedor de forma significativa e positiva na seguinte ordem: experiência prévia do fundador, idade e nível educacional.

O que pode se extrair dos estudos apresentados são os seguintes aspectos: a) existem no momento muitas atividades e pesquisas sendo realizadas no campo da educação empreendedora nas universidades ao redor do mundo; b) a importância da educação empreendedora nas universidades como fomentadora da intenção e orientação empreendedora nos jovens universitários; c) as características empreendedoras influenciam o comportamento do empreendedor de forma positiva e significativa, embora elas variem entre esses estudos; d) o histórico familiar e nível educacional, notadamente nível universitário, aparecem como características no empresário já estabelecido.

\section{Aspectos Metodológicos}

Essa pesquisa é aplicada quanto a sua natureza e com objetivo descritivo porque busca descrever e relatar as características comportamentais empreendedoras de um grupo de alunos de um curso de Administração de uma IES situada na Região Metropolitana de SP. A estratégia de abordagem é de um levantamento desse grupo de alunos.

A amostra consistiu de alunos do $5^{\circ}$ período que estavam cursando a disciplina de Empreendedorismo I no $2^{\circ}$ semestre de 2013 e no $1^{\circ}$ semestre de 2014 , per- fazendo um total de 79 alunos respondentes, correspondente a $70 \%$ do total de alunos desses dois períodos.

Foi utilizado como instrumento de coleta de dados o questionário de 60 perguntas (55 para cálculo dos CCEs e cinco para cálculo do fator de correção das escalas) desenvolvido por McClelland e descrito em Mansfileld et al (1987). A escala dos fatores constituintes das características comportamentais empreendedoras (CCE) foi alterada a partir da escala das respostas às perguntas, que passou de uma escala Likert de 5 pontos para uma de 10 pontos. Assim, a pontuação máxima de cada CCE passou de 25 para 50 pontos, em que o mínimo para que seja considerado empreendedor, passou de 15 para 30 pontos, sem impacto.

Adotou-se uma escala de 10 pontos nessa escala Likert, na qual se procurou aproximar a escala ordinal à escala razão e, assim, considerar que as distâncias entre os pontos dela possam ser consideradas homogêneas, permitindo, além das análises não paramétricas, o uso de técnicas paramétricas como Análise Fatorial e Teste t de Student.

Os códigos utilizados para identificar as 10 CCEs daqui em diante estão no Quadro 2.

\begin{tabular}{|c|c|}
\hline Código & $\begin{array}{c}\text { Características Comportamentais } \\
\text { Empreendedoras (CCE) }\end{array}$ \\
\hline BOI & Busca de oportunidades e iniciativa \\
\hline PER & Persistência \\
\hline COM & Comprometimento \\
\hline EQE & Exigência de qualidade e Eficiência \\
\hline CRC & Correr Riscos Calculados \\
\hline EM & Estabelecimento de Metas \\
\hline BI & Busca de Informações \\
\hline PMS & Planejamento e Monitoramento Sistemáticos \\
\hline PRC & Persuasão e Rede de Contatos \\
\hline IAC & Independência e Autoconfiança \\
\hline
\end{tabular}

Quadro 2: Códigos das CCE

Fonte: Elaborado pelos autores deste artigo

Os métodos estatísticos utilizados nesse estudo e seus respectivos objetivos foram os descritos no Quadro 3. 


\begin{tabular}{|c|c|c|c|}
\hline OBJEtivo & VARIÁVEIS & MÉTODo & ITEM \\
\hline $\begin{array}{c}\text { Identificar a } \\
\text { segmentação da } \\
\text { população pelos } \\
\text { atributos de estudo }\end{array}$ & $\begin{array}{c}\text { Interesse em } \\
\text { empreender } \\
\text { É empreendedor? } \\
\text { Sexo do } \\
\text { respondente }\end{array}$ & $\begin{array}{l}\text { Análise de } \\
\text { Frequência }\end{array}$ & 4.1 \\
\hline $\begin{array}{c}\text { Analisar o } \\
\text { comportamento } \\
\text { das características } \\
\text { comportamentais } \\
\text { empreendedoras }\end{array}$ & 10 CCEs & Estatística Descritiva & 4.2 \\
\hline $\begin{array}{c}\text { Analisar o } \\
\text { comportamento } \\
\text { dos respondentes } \\
\text { de acordo com os } \\
\text { atributos de estudo }\end{array}$ & 10 CCEs & $\begin{array}{c}\text { ANOVA: } \\
\text { segmentação } \\
\text { da propensão } \\
\text { a empreender } \\
\text { declarada pelos } \\
\text { respondentes. } \\
\text { Teste t-Student: } \\
\text { identificar a } \\
\text { influência do sexo } \\
\text { dos respondentes. }\end{array}$ & 4.3 \\
\hline $\begin{array}{c}\text { Analisar a existência de } \\
\text { fatores latentes dentro } \\
\text { das características } \\
\text { empreendedoras }\end{array}$ & 10 CCEs & $\begin{array}{l}\text { Análise Fatorial: } \\
\text { Descoberta de } \\
\text { fatores latentes } \\
\text { Validação mediante: } \\
\text { teste KMO e teste } \\
\text { de esfericidade } \\
\text { de Bartlett. }\end{array}$ & 4.4 \\
\hline $\begin{array}{c}\text { Analisar o } \\
\text { comportamento da } \\
\text { variável que representa } \\
\text { o valor agregado } \\
\text { da predisposição } \\
\text { em empreender }\end{array}$ & EMP & $\begin{array}{l}\text { Análise da variável } \\
\text { latente EMP }\end{array}$ & 4.5 \\
\hline
\end{tabular}

Quadro 3: Métodos estatísticos

Fonte: Elaborado pelos autores deste artigo

A Análise Fatorial, considerando primeiramente as 55 perguntas do instrumento de McClelland (PALETTA, 2001) e logo após, os 10 CCEs, pretendeu identificar a existência de fatores latentes constituídos por agrupamentos das variáveis estudadas, que explicassem, de uma forma racionalizada, a característica comportamental da população e, assim, caracterizar o comportamento empreendedor da população sob estudo, permitindo uma melhor sistematização do entendimento do fenômeno. O Teste de Confiabilidade mediante a apuração do valor do Alfa de Cronbach foi usado para validar os aspectos de unidimensionalidade do conjunto de variáveis que formam o fator latente definido pela Análise Fatorial.

O Test $t$ de Student foi utilizado para identificar a presença de diferenças comportamentais refletidas nos valores dos CCEs, devidas ao sexo dos respondentes.
A Análise de Variância, ANOVA, foi utilizada para identificar a presença de diferenças comportamentais refletidas nos valores dos CCEs, segundo os critérios de interesse em empreender declarada pelos respondentes (baixo, médio ou alto).

Com o objetivo de determinar a propensão de um indivíduo a ser ou não um potencial empreendedor, a partir das cargas fatoriais resultantes da Análise Fatorial, foi proposto um modelo de Regressão Linear Multivariada (variável EMP), tendo os fatores CCEs como variáveis preditoras.

Foram analisadas ainda as correlações entre os CCEs para permitir um melhor entendimento das possíveis causas da significância dos resultados das análises Fatorial, t de Student e ANOVA.

\section{Análise dos Resultados}

Seguem os resultados comentados das análises estatísticas mencionadas no Quadro 4.

\subsection{Análise de Frequência}

A amostra wcom 79 respostas de alunos do curso de graduação em Administração está segmentada conforme segue:

\begin{tabular}{|c|c|c|c|c|c|}
\hline \multicolumn{3}{|c|}{$\begin{array}{l}\text { GRAU DE INTERESSE DO RES- } \\
\text { PONDENTE EM ABRIR NEGÓCIO }\end{array}$} & \multicolumn{3}{|c|}{ SEXo do RESPONDENTE } \\
\hline \multicolumn{3}{|c|}{ FrEQUÊNCIA } & \multicolumn{3}{|c|}{ FREQUÊNCIA } \\
\hline Já possuo & 1 & $1,30 \%$ & Fem & 48 & $60,8 \%$ \\
\hline $\begin{array}{l}\text { Baixo } \\
\text { interesse }\end{array}$ & 17 & $21,50 \%$ & Masc & 31 & $39,2 \%$ \\
\hline $\begin{array}{l}\text { Médio } \\
\text { interesse }\end{array}$ & 24 & $30,40 \%$ & Total & 79 & $100 \%$ \\
\hline $\begin{array}{c}\text { Alto } \\
\text { interesse }\end{array}$ & 37 & $46,80 \%$ & & & \\
\hline Total & 79 & $100 \%$ & & & \\
\hline \multicolumn{3}{|c|}{$\begin{array}{l}\text { A família do respondente } \\
\text { tem negócio próprio? }\end{array}$} & \multicolumn{3}{|c|}{$\begin{array}{l}\text { Já trabalha (ou) no } \\
\text { negócio da família? }\end{array}$} \\
\hline & \multicolumn{2}{|c|}{ Frequência } & & \multicolumn{2}{|c|}{ Frequência } \\
\hline Não & 50 & $63,3 \%$ & Não & 51 & $64,60 \%$ \\
\hline Sim & 29 & $36,7 \%$ & Sim & 28 & $35,40 \%$ \\
\hline Total & 79 & $100 \%$ & Total & 79 & $100 \%$ \\
\hline
\end{tabular}

Quadro 4: Segmentação das respostas da pesquisa Fonte: Elaborado pelos autores deste artigo 
Percebe-se um alto percentual $(46,8 \%)$ de alunos com alto interesse em abrir seu negócio próprio. Essa resposta pode ter sido influenciada pelo histórico familiar em negócios, à semelhança dos achados nos estudos de Kume et al. (2013) e Gurol e Atsan (2006), em que parte da família dos respondentes ter negócio próprio ou do respondente ter trabalhado em negócio da família.

\subsection{Análise da Estatística Descritiva}

Foram executados dois testes de aderência à Distribuição Normal, o de Kolmogorov-Smirnov e o de Shapiro-Wilks e ambos indicam aderência significativa à Distribuição Normal, que é um requisito desejável para o uso da Análise Fatorial, com Nível de Confiança de $99 \%$.

Os diagramas Box-Plot demonstram graficamente a distribuição de cada CCE. Relembrando que a escala do presente estudo é duas vezes maior que a correspondente de McClelland presente em Paletta (2001) e Mansfileld et al. (1987), assim, valores acima de 15 para McClelland devem ser interpretados como 30 na Figura 1. Notar que o limite inferior de praticamente todas as variáveis CCEs, as caixas do Box-Plot, que corresponde ao limite do primeiro Quartil, está próximo de 30 (equivalente a 15 de McClelland). Isso indica que a população pesquisada apresenta comportamento com alguma propensão a empreender (mediana acima de 30 em todas as métricas analisadas).

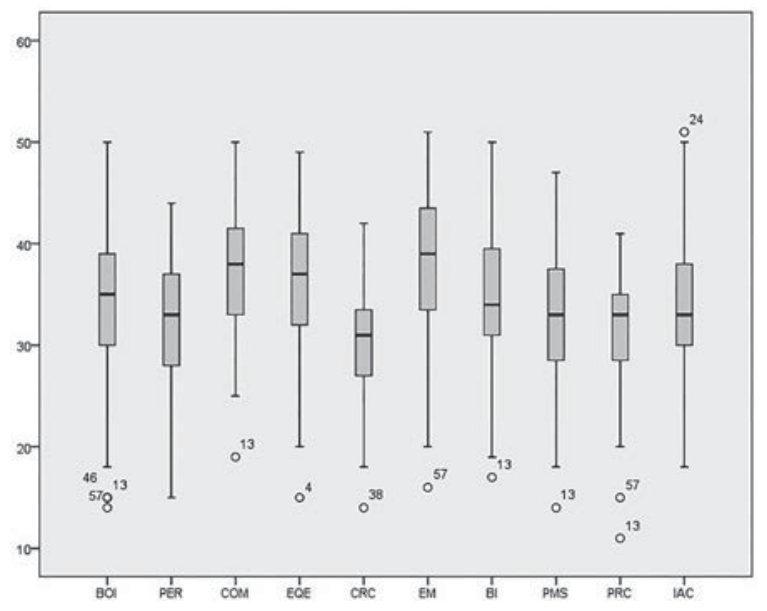

Figura 1: Diagramas Box-Plot das CCEs

Fonte: Elaborada pelos autores deste artigo
As avaliações das CCEs da amostra coletada foram comparadas com os resultados dos artigos de Bartel (2010), Carvalho e Zuanazzi (2003) e Feger et al. (2008) e para tal, a escala utilizada foi ajustada para permitir a comparação, refletida nas médias e desvios-padrões das variáveis. Os valores foram apresentados de acordo com o valor médio decrescente das variáveis e determinou-se a distância como o valor posicional entre as variáveis comparadas. O Quadro 5 apresenta os resultados indicando que existe alto grau de concordância nos valores obtidos nos estudos considerados.

Os resultados obtidos da amostra estudada mostram boa aderência àqueles obtidos nos valores médios e de desvio-padrão dos fatores CCEs nos estudos anteriores que foram contrastados e apresentados no Quadro 5. Observar que as distâncias são preponderantemente pequenas ( 0 e 1 ) no comparativo do ranking das CCEs dos estudos mencionados. Foram observados poucos casos com distância até três. A característica EM aparece como sendo a primeira em todos os estudos (maior valor médio dentre as demais CCEs), seguido pela COM em que apenas Bartel aponta como o terceiro no ranking. Por outro lado, as características PMS, PER, PRC e CRC aparecem na parte inferior do ranking em todos os estudos. Esses resultados permitem sugerir um resultado descritivo do fenômeno em estudo baseado nas métricas propostas por McClelland presentes em Mansfileld et al. (1987) e Paletta (2001).

Os resultados de Izedonmi e Okafor (2010) mostram criatividade e inovação como as mais importantes características seguidas de estabilidade emocional e confiança (segunda característica) e busca de oportunidade (terceira). As $2^{\mathrm{a}}$ e $3^{\mathrm{a}}$ características são equivalentes ao IAC e BOI que estão no meio do ranking do Quadro 4 ao passo que criatividade e inovação não encontram paralelo no nosso estudo. 


\begin{tabular}{|c|c|c|c|c|c|c|c|c|c|}
\hline & $\begin{array}{c}\text { RANKING } \\
\text { BASEADO } \\
\text { NA MÉDIA } \\
\text { DA VARIÁ- } \\
\text { VEL }\end{array}$ & $\begin{array}{l}\text { BARTEL } \\
(2010)\end{array}$ & DifERENÇA & $\begin{array}{c}\text { Carvalho; } \\
\text { ZuANazZi } \\
\text { (2003) }\end{array}$ & DifERENÇA & $\begin{array}{c}\text { FeGER } \\
\text { ET AL. } \\
(\mathbf{2 0 0 8 )}\end{array}$ & $\begin{array}{c}\text { EMPREEN } \\
\text { DEDOR } \\
\text { PRIVADO }\end{array}$ & $\begin{array}{c}\text { FEGER } \\
\text { ET AL. } \\
(\mathbf{2 0 0 8 )}\end{array}$ & $\begin{array}{c}\text { EMPREEN } \\
\text { DEDOR } \\
\text { SOCIAL }\end{array}$ \\
\hline EM & 10 & EM & 0 & EM & 0 & EM & 0 & EM & 0 \\
\hline $\mathrm{COM}$ & 09 & BI & 2 & $\mathrm{COM}$ & 0 & $\mathrm{COM}$ & 0 & $\mathrm{COM}$ & 0 \\
\hline EQE & 08 & $\mathrm{COM}$ & 1 & IAC & 2 & BOI & 3 & BI & 1 \\
\hline BI & 07 & IAC & 1 & EQE & 1 & EQE & 1 & IAC & 1 \\
\hline IAC & 06 & BOI & 1 & BI & 1 & $\mathrm{BI}$ & 1 & BOI & 1 \\
\hline BOI & 05 & EQE & 1 & BOI & 0 & IAC & 1 & EQE & 3 \\
\hline PMS & 04 & PMS & 0 & PER & 1 & PER & 1 & PER & 1 \\
\hline PER & 03 & PER & 0 & PMS & 1 & PMS & 1 & PMS & 1 \\
\hline PRC & 02 & PRC & 0 & PRC & 0 & CRC & 1 & PRC & 0 \\
\hline $\mathrm{CRC}$ & 01 & $\mathrm{CRC}$ & 0 & CRC & 0 & PRC & 1 & $\mathrm{CRC}$ & 0 \\
\hline
\end{tabular}

Quadro 4: Características comportamentais empreendedoras

Fonte: Elaborado pelos autores deste artigo

\subsection{Teste da Diferenciação da Capacidade Empreendedora Baseada nos 10 Fatores CCE}

O Teste ANOVA baseado na variável de interesse em empreender (P57 = baixo, médio e alto interesse), aplicado sobre o conjunto dos 10 fatores CCE, resultou em Sig maior que $5 \%$ para todos os fatores, exceto IAC que apresentou Sig = 0,04 no teste post-hoc Scheffé. Assim, os nove fatores, exceto IAC não apresentaram diferenças significativas que pudessem ser aludidas à declaração de interesse em empreender dos respondentes (variável P57). O fator IAC indicou existir diferença na opinião dos respondentes que responderam alto interesse em empreender, comparativamente aos de baixo interesse, com Nível de Confiança de 95\%. O médio interesse não apresentou diferença significativa do baixo e também do alto interesse em empreender.

O Teste t de Student baseado no Sexo dos respondentes resultou um valor de Sig menor que $5 \%$ nos CCEs PRC ( $\mathrm{Sig}=0,050)$ e IAC $(\mathrm{Sig}=0,03)$, indicando que existe diferença devido ao sexo dos respondentes nesses CCEs, com um Nível de Confiança de 95\%. Os demais fatores não apresentaram diferenciação pelo sexo do respondente.

\subsection{Análise Fatorial}

A Análise Fatorial dos 10 fatores CCEs atende a relação mínima de 1:5, isso é, 5 casos na amostra para cada variável de estudo, conforme sugerido por Hair et al. (2005, p. 97). Foram utilizados três métodos de validação para a verificação de significância dos resultados desta técnica: Matriz de Correlação de Anti-Imagem, KMO Kaiser-Mayer-Olkin e Bartlett.

Os resultados da análise da matriz de correlações de anti-imagem, que mostra a conveniência da permanência de variáveis na determinação dos fatores latentes da Análise Fatorial, indicaram que todas as variáveis possuem qualidade para permanecerem no processo de análise fatorial.

Os valores extremos presentes na matriz de correlações de anti-imagem, em que aqueles na diagonal principal devem ser altos (próximos de 1,0) e fora da diagonal principal devem ser baixos (abaixo de $0,5)$, indicam boas condições técnicas para aplicação da técnica de análise fatorial. Os valores obtidos da amostra foram os seguintes: i) na diagonal principal, valores entre 0,88 e 0,98, considerados altos; ii) fora da diagonal principal apresentaram valores entre 0,5 e - 0,44 , considerados baixos. Portanto, adequados à aplicação da técnica da Análise Fatorial. 
O teste $\mathrm{KMO}$ de adequabilidade da amostra com 0,90 indica que o resultado obtido é significativo para as conclusões, já que valores acima de 0,8 já são considerados "admiráveis" do ponto de vista de qualificação da amostra (HAIR et al., 2005, p.98).

O Teste de Esfericidade de Bartlett resultou em um valor-p de $0,00 \%$, indicando a significância das correlações entre os fatores CCEs e apoiando a conveniência da Análise Fatorial, com Nível de Confiança de 95\%.

A Análise Fatorial resultou em um único fator englobando os 10 fatores CCE com variância total explicada de $60,16 \%$ indicando que esse fator tem capacidade de explicar $60,16 \%$ da variabilidade do fenômeno e que os demais $40 \%$ são devidos a outros fatores não presentes no estudo.

Bartel (2010) analisou as dimensões do fenômeno em duas ferramentas. Na Análise Fatorial dois fatores foram identificados que perfazem uma capacidade explicativa de $61,20 \%$, muito próximo do nosso estudo com apenas um fator.

Em outra passagem do trabalho de Bartel (2010), ele apresentou os pesos das variáveis CCEs em três eixos. Nota-se que o Eixo 1 apresenta as maiores cargas fatoriais das CCEs (entre 0,628 e 0,727) comparativamente às cargas fatoriais dos demais eixos (cujas cargas fatoriais atingiram, no máximo, 0,544), o que identifica a presença de um fator latente contendo as 10 variáveis CCEs. Isso aproxima o comportamento ao que foi observado na amostra do nosso estudo.

Nenhum dos estudos apresentados, exceto do Bartel, utilizou Análise Fatorial nos seus resultados, apesar de não apresentarem qualquer tipo de restrição para seu uso.

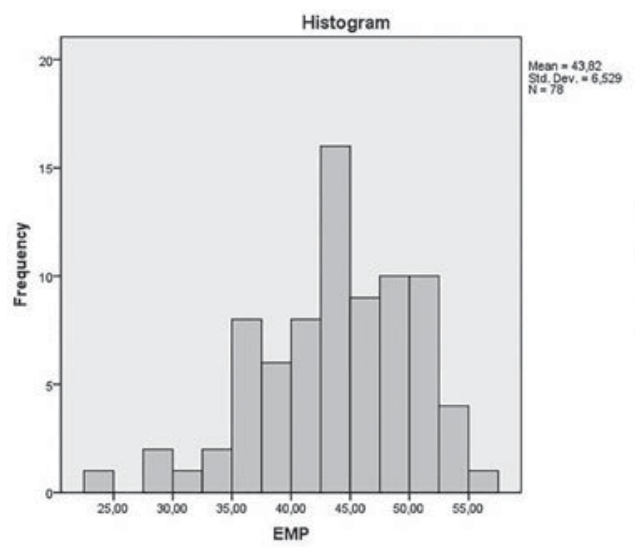

Figura 2: Histograma e Curva Normal Q-Q da variável EMP Fonte: Elaborada pelos autores deste artigo
Os testes de significância mencionados apresentaram condições técnicas adequadas para a proposição de um modelo matemático de regressão linear que representa o grau de disposição em empreender. Assim, a capacidade explicativa da variável latente resultante da Análise Fatorial de 60,16\% da variância observada instiga a proposição de um modelo linear a partir da matriz dos coeficientes, que mede a propensão a empreender, conforme segue:

$\mathrm{EMP}=\mathrm{BOI} * 0,190+\mathrm{PER} * 0,143+\mathrm{COM} * 0,138$ $+\mathrm{EQE} * 0,114+\mathrm{CRC} * 0,170+\mathrm{EM} * 0,138+\mathrm{BI}$ $* 0,115+$ PMS * $0,170+$ PRC *0,17+ IAC *0,180

\subsection{Análise da Variável Latente EMP}

A variável EMP, definida como a representação matemática do fator latente estabelecido na Análise Fatorial, foi analisada em seu comportamento, conforme segue.

A Estatística Descritiva da variável EMP mostra graficamente, pela Figura 2, um comportamento bastante razoável de ajuste à Curva Normal na faixa de valores de 35 a 55 com algum descolamento do ajuste nos seus valores extremos, o que pode ensejar a consideração de estender as conclusões do presente estudo à população alvo, ainda que, quantitativamente, o teste de Kolmogorov-Smirnov com Nível de Confiança de $95 \%$ tenha rejeitado a hipótese da normalidade com Sig=0,0. O histograma e a Curva Normal QQ mostram graficamente o comportamento da variável agregada EMP confirmando a propensão a empreender da população investigada já mencionada por outras ferramentas estatísticas utilizadas.

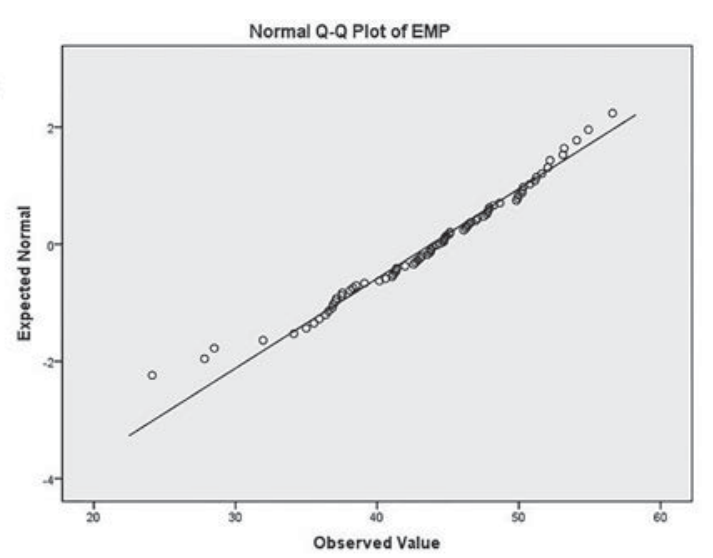


A partir da equação de regressão linear multivariada que agrega a contribuição dos 10 fatores CCEs, foi realizado o teste de confiabilidade (Alfa de Cronbach) para analisar o comportamento dos respondentes frente a esse fator.

O Teste de Confiabilidade (Alfa de Cronbach) resultou um valor do coeficiente $=0,94$, que é considerado alto.

Em seguida, foi feita uma análise para determinar se algum dos fatores CCE poderia ser retirado do conjunto visando aumentar o valor do Alfa de Cronbach e, consequentemente, a qualidade do modelo. O que se observou também é que nenhum dos 10 CCEs, caso fosse retirado do modelo, melhoraria o seu desempenho e poderia resultar uma redução no valor do Alfa de Cronbach $(0,94)$. Conclui-se, portanto, que todos os fatores CCE contribuem para a qualidade do modelo.

\section{Considerações Finais}

As análises permitiram atingir o objetivo do artigo que foi analisar as características comportamentais empreendedoras nos estudantes de uma IES da região metropolitana de São Paulo e comparar com os resultados obtidos em estudos correlatos realizados no Brasil e exterior. No primeiro objetivo, a análise descritiva mostrou que as características mais desenvolvidas foram: Estabelecimento de Metas e Comprometimento. Enquanto as menos desenvolvidas foram: Persuasão e Correr Riscos Calculados, cabe colocar que, mesmo sendo as menos desenvolvidas, ainda assim, apresentaram pontuação superior a 15 pontos, que é considerada segundo McClelland como o patamar inicial para a propensão a empreender.

Comparando a classificação das características pelas suas pontuações obtidas no presente estudo $e$ as demais aplicações anteriores, vemos que as pontuações obtidas são similares as dos demais, obtendo-se, assim, um ranking das CCEs similar entre a mostra presente e a de Bartel (2010), Carvalho e Zuanazzi (2003) e Feger et al. (2008).

O grau médio e alto de interesse em empreender manifestado pelos respondentes do presente artigo, totalizando $77 \%$, em um cenário presente em que $37 \%$ pertencem a famílias que já possuem negócio próprio e $35 \%$ trabalham ou já trabalharam neste negócio, estão refletidos nos valores acima de 15 nas variáveis características comportamentais empreendedoras.

O sexo dos respondentes diferenciou o comportamento captado pelos fatores PRC (Persuasão e Rede de Contatos) e IAC (Independência e Auto Confiança), mas os demais fatores se mostraram insensíveis ao sexo do respondente, com nível de confiança de $95 \%$.

A Análise Fatorial dos 10 fatores CCEs permitiu identificar um comportamento significativo de constituição de um único variável latente, com nível de confiança de $95 \%$ e assim, a proposição de um fator único que possa representar o nível de propensão a empreender, aqui denominado EMP, de "Propensão a Empreender". A característica Busca por Oportunidades e Iniciativa com 0,19 aparece com o maior peso enquanto a característica Exigência de qualidade e Eficiência com 0,11 aparece com o menor peso sobre a propensão a empreender.

A proposição do fator EMP, avaliação mais abrangente do grau de propensão a empreender, permite perceber em uma única escala, tal comportamento, o que se mostra mais facilitado comparativamente à análise de 10 fatores CCEs de McClelland com 10 características comportamentais que representam, individualmente, características muito marcantes $e$ diferenciadas e onde o autor indica que valores medianos de cada fator CCE caracterizam propensão a empreender.

O fator EMP permite perceber a propensão a empreender de forma integrada e abre a oportunidade de pesquisa, não explorada no presente artigo, de investigar o efeito compensatório dos valores de cada um dos 10 CCEs sobre a intensidade da propensão a empreender. Também, como sugestão de estudos futuros, essa análise poderia ser feita com executivos de empresas e comparar seus resultados com os empreendedores no sentido de verificar se existem diferenças entre eles.

Uma limitação desse estudo foi o tamanho da amostra que contou com $70 \%$ de respondentes ao questionário. 


\section{REFERÊNCIAS}

ÁLVAREZ-HERRANZ, A.; VALENCIA-DE-LARA,

P.; MARTINEZ-RUIZ, M. P. How entrepreneurial characteristics influence company creation: a crossnational study of 22 countries tested with panel data methodology. Journal of Business Economics and

Management, [S.l.], v. 12, n. 3, p. 529-545, 2011.

BATISTA, C. H. Estudo comparativo do

desenvolvimento das características comportamentais empreendedoras dos alunos da disciplina de empreendedorismo durante o primeiro semestre letivo de 2004 nos cursos de administração e turismo \& lazer da FURB. 2004. 107 p. Dissertação (Mestrado) - Universidade Regional de Blumenau, Blumenau, 2004.

BARTEL, G. Análise da evolução das características comportamentais empreendedoras dos acadêmicos do curso de administração de uma IES catarinense. 106 p. Dissertação de Mestrado. Universidade Regional de Blumenau. Blumenau, 2010.

BORNIA, Antônio Cezar et al. Atitude empreendedora: validação de um instrumento de medida com base no modelo de resposta gradual da teoria da resposta ao item.

Revista de Administração Mackenzie, São Paulo, v. 14, n. 5, p. 230-251, 2013.

CAMARA, E. C.; ANDALÉCIO, A. M. L. Características empreendedoras: um estudo de caso com farmacêuticos utilizando o modelo de McClelland. Revista de

Empreendedorismo e Gestão de Pequenas Empresas, [S.I.], v. 1, n. 3, p.64-77, 2012.

CARVALHO, C.; ZUANAZZI, J.; Análise das características de alunos de graduação em Administração e sua relação com as expectativas do ensino de empreendedorismo. In: EGEPE - ENCONTRO DE ESTUDOS SOBRE EMPREENDEDORISMO E GESTÃO DE PEQUENAS EMPRESAS. UEM/UEL/UnB, Brasília, DF, 2003. Anais... EGEPE, Brasília, DF, 2003. p. 125-141.

DEPOSITARIO, D.; AQUINO, N.; FELICIANO, K.; Entrepreneurial Skill Development Needs of Potential Agri-Based Thechnopreneus. ISSAAS Journal, [S.l.], v. 1, p.106-120, 2011.
DOLABELA, F. Oficina do empreendedor: a metodologia de ensino que ajuda a transformar conhecimento em riqueza. Rio de Janeiro: Sextante, 2008.

DORNELAS, J. C. A. Empreendedorismo: transformando idéias em negócios. 3. ed. Rio de Janeiro: Elsevier, 2008.

FEGER, José Elmar et al. A. Empreendedores sociais e privados: reflexões sobre suas características comportamentais. Revista Gestão Organizacional (RGO), [S.I.], v. 1, p.102-118, 2008.

FONSECA, G.; MUYLDER, C. Auto-percepção do perfil McClelland: um estudo de caso Empretec. Revista Ciências Sociais em Perspectiva, [S.I.], v. 9, n. 16, 2010.

GEM, Global Entrepreneurial Monitor.

Empreendedorismo no Brasil: relatório executivo. 2013. Disponivel em: < http://www.sebrae.com.br/Sebrae/ Portal\%20Sebrae/Anexos/Relatorio\%20Executivo\%20 GEM\%202013.pdf> Acesso em: $1^{\circ}$ out. 2014.

GUROL, Y.; ATSAN, N. Entrepreneurial characteristics amongst university students. Education and Training, [S.l.], v. 18, n. 1, p. 25-38, 2006.

HAIR, Jr, Joseph F. et al. Análise Multivariada de Dados. 5. ed. Tradução Adonai Schlup Sant'Anna e Anselmo Chaves Neto. Porto Alegre: Bookman, 2005. p. 593.

IZEDONMI, P. F; OKAFOR, C. The effects of entrepreneurship education of students' entrepreneurial intentions. Global Journal of Management and Business Research, [S.I.], v. 10, n. 6, p. 49-60, 2010.

KRISTIANSEN, S.; INDARTI, N.; Entrepreneurial Intention among Indonesian and Norwegian Students. Journal of Enterprising Culture, [S.l.], v. 12, p. 55-78, 2004.

KUME, A.; KUME, V.; SHAHINI, B. Entrepreneurial characteristics amongst university students in Albania. European Scientific Journal, [S.l.], v. 9, n. 16, p. 206225, 2013.

LIMA, Edmilson et al. Intenções e Atividades Empreendedoras dos Estudantes Universitários. Relatório do Estudo GUESS Brasil, [S.l.]: [s.n.], 2011. 
LOPEZ JUNIOR, G.; SOUZA, E. Instrumento de Medida da Atitude Empreendedora - IMAE: Construção e Validação de uma Escala. In: $30^{\circ}$ ENCONTRO DA ANPAD (ASSOCIAÇÃO NACIONAL DE PÓSGRADUAÇÃO E PESQUISA EM ADMINISTRAÇÃO). Salvador, 2006. Anais. Salvador, ANPAD, Salvador, 2006. 14 p.

MANSFILELD, R. S. et al. The identification and assessment of competencies and other personal characteristics of entrepreneurs in developing countries. Boston, Massachusetts, United States: McBer and Company. 1987.

MENEZES, L. C. M. Gestão de Projetos. 2. ed. São Paulo: Atlas, 2003.

NASCIMENTO, Thiago Cavalcante et al. A Metodologia de Kristiansen e Indarti para Identificar Intenção empreendedora em Estudantes de Ensino Superior: Comparando Resultados Obtidos na Noruega, Indonésia e Alagoas. VI ENCONTRO DE ESTUDOS SOBRE EMPREENDEDORISMO E GESTÃO DE PEQUENAS EMPRESAS. Recife: Anais... Recife. 2010.

OLIVEIRA, J. M. Lócus de controle e a efetividade empresarial em microempresários do estado do Rio Grande do Norte. 2010. 105 p. Tese (Mestrado) - Universidade Federal do Rio Grande do Norte, Natal, 2010.

PADILLA-MELÉNDEZ, A.; FERNÁNDEZ-GÁMEZ, M. A.; MOLINA-GÓMEZ, J. Feeiling the risks: effects of the development of emotional competences with outdoor training on the entrepreneurial intent of university students. International Entrepreneurial Management, [S.l.], v. 10, p. 861-884, 2014.

PALETTA, M. A. Vamos abrir uma pequena empresa: um guia prático para abertura de novos negócios. Campinas, SP: Alínea, 2001.

SANTOS, P. Uma Escala para Identificar Potencial Empreendedor. 2008. 366 p. Tese (Doutorado) Universidade Federal de Santa Catarina, Florianópolis, 2008.

SEBRAE. Curso aprender a empreender. [S.l.]: [s.n.], 2007. (Apostilas e vídeo
SILVA, K. A. F. Determinantes Comportamentais e Socioeconômicos da propensão a empreender de concludentes de administração em IES de Teresina - Piauí. 2009. 144 p. Tese (Mestrado) - Universidade de Fortaleza. Fortaleza, 2009.

SOUZA, E. C. L. de. A disseminação da cultura empreendedora e a mudança na relação universidade-empresa. Empreendedorismo: competência essencial para pequenas e médias empresas. Brasília, DF: ANPROTEC, 2001. p. 28-41. et al. Métodos, técnicas e recursos didáticos de ensino do empreendedorismo em IES brasileiras. São Paulo: Atlas, 2006. p. 200-216.

SUTANTO, E. M.; ELIYANA, A. The study of entrepreneurial characteristics with achievement motivation and attitude as the antecedent variables. International Refereed Research Journal, [S.I.], v. 4, p. 125-134. 2014.

TOLEDO, L. T. et al. Identificação de Características Empreendedoras em Empreendedores Alagoanos. In: VIII SEGeT - SIMPÓSIO DE EXCELÊNCIA EM GESTÃO E TECNOLOGIA. Resende, 2011. Anais... Resende, Brasil. 2011.

UNCTAD. Empretec Programme -The Entrepreneur's Guide. Geneva, Switzerland. 2010.

VASCONCELOS, V. Comportamento Empreendedor dos Proprietários-Dirigentes de Micro e Pequenas Empresas do Setor de Confecções (Vestuário) de Teresina/PI. 2011. 98 p. Dissertação (Mestrado) Universidade de Fortaleza, Fortaleza. 2011. 